Int. J. Adv. Eng. Pure Sci., Special Issue-I: e33-e40

DOI: 10.7240/jeps.468963

RESEARCH ARTICLE / ARAŞTIRMA MAKALESI

\title{
Uzay ve Havacılık Alaşımlarının Elektriksel Erozyonla Delinmesi İşleminde Yüzey Bütünlügünün İncelenmesi
}

\author{
Investigation of Surface Integrity of Aerospace Alloys Drilled by Micro Electrical Discharge \\ Machining
}

\author{
Tohid ABBASI ${ }^{1}(\mathbb{D})$, Merve EKICI ${ }^{1}{ }^{(\mathbb{D})}$, Oğuzhan YILMAZ ${ }^{1}$ \\ ${ }^{1}$ Gazi Üniversitesi, Mühendislik Fakültesi, Makine Mühendisliği Bölümü, 06570, Ankara, Türkiye
}

$\ddot{O} \mathbf{z}$

Elektro Erozyon ile İşleme (EEI), iş parçasının ergitilmesi ve elektrot malzemesinin buharlaştırılmasına dayanan geleneksel olmayan işleme yöntemlerinden biridir. Bu çalışmada, havacılık uzay endüstrisinde sıklıkla kullanılan Ti-6Al-4V ve Inconel 718 alaşımları, bakır ve pirinç elektrot malzemesi kullanılarak EEİ ile delinmiş ve deliklerin yüzey bütünlüğü incelenmiştir. Deliklerin giriş ve çıkış çapları ölçülmüş ve delik yüzeylerinde yeniden katılaşmış katman, Taramalı Elekron Mikroskobisi (SEM) ve Enerji Dağılım Spektrometresi (EDS)kullanılarak incelenmiştir. Yapılan deneylerden elde edilen sonuçlara göre, işlem sırasında düşük elektrot çapları kullanıldığında daha yüksek delik çap büyümesi ile karşılaşılmıştır. Bakır yerine pirinç elektrot kullanıldığında ise çap büyümesi azalmakta yeniden katılaşmış katman kalınlığı ise artmaktadır. Inconel 718 alaşımında elde edilen yüzeylere kıyasla hem bakır hem de pirinç elektrot ile delinmiş Ti-6Al-4V alaşımının işlenmiş yüzeylerinde daha yüksek oranda yüzey çatlakları ile karşılaşılmıştır. Her iki elektrot tipi için Inconel 718 alaşımında elde edilen yüzey pürüzlülüğü Ti-6Al-4V alaşımına göre daha düşüktür. Ti-6Al-4V alaşımının EEİ işleminde bakır yerine pirinç elektrot kullanıldığında ise yüzey pürüzlülüğü artmaktadır.

Anahtar Kelimeler: Elektro erozyon ile işleme, Ti-6Al-4V, Inconel 718, yüzey bütünlüğü

\begin{abstract}
Electrical discharge Machining (EDM) is one of the non-conventional machining process available, in which material removal takes place due to melting and vaporization of electrode materials. In present work, Ti-6Al-4V alloy and Inconel 718 alloy which are widely used in aerospace industry, were drilled with EDM where brass and copper were used as electrode materials. The objective of this study is to investigate the surface integrity of Ti-6Al-4V alloy and Inconel 718 alloy after EDM. For this purpose, inlet and outlet diameters of EDM-drilled holes and white layer thicknesses of drilled hole surfaces were measured and microstructure of hole surfaces was analyzed using Scanning Electron Microscopy (SEM) and Energy Dispersive (EDS) analysis. The experimental results are as fallows: The smaller the diameter of electrode, the higher the overcut ratio. When brass electrode was used rather than copper electrode, over cut ratio decreased and white layer thickness increased. Independent of the electrode material, more intense micro cracks were seen on the Ti-6Al-4V alloy's hole surface as compared to Inconel 718 alloy. Independent of the electrode material, surface roughness of the Inconel 718 alloy is less than the Ti-6Al-4V alloy. Surface roughness increased on the Ti-6Al-4V alloy when brass electrode was used rather than copper electrode.
\end{abstract}

Keywords: Electrical discharge Machining, Ti-6Al-4V, Inconel 718, Surface Integrity

\section{I.GİRIŞ}

Ti-6AL-4V ve Inconel 718 alaşımları işlenmesi zor olarak değerlendirilen ve yüksek sıcaklıklarda mukavemetlerini korumaları nedeniyle uzay ve havacılık uygulamalarında kullanılan süper alaşımlardandır. Titanyum (Ti), çeliğe göre yaklaşık \%56 daha düşük yoğunluğa sahip olmasına rağmen yüksek özgül dayanıma sahip bir elementtir. Titanyum ayrıca korozyona dayanımı ve biyo uyumluluğu yüksek bir malzeme olarak tanımlanır. Titanyum alaşımları arasında, Ti-6Al-4V yaygın olarak kullanılan alaşımdır ve iyi performans gösterir. Ti-6Al-4V alaşımı, içerisinde ana element olarak yer alan Alüminyum 
ve Vanadyum sayesinde yüksek mukavemetli, düşük ağırlık oranı, düşük elastisite modülü, düşük 1sıl iletkenlik ve mükemmel korozyon direncine sahip bir alfa-beta titanyum alaşımıdır. Nikel-krom-molibden esaslı bir alaşım olan Inconel 718, yüksek sıcaklıklarda mukavemetini koruyabilen, yüksek korozyon direncine sahip ve kopma-kırılma direnci yüksek bir alaşım malzemesidir. Bu alaşımlardan üretilen parçalar otomotiv endüstrisinde, havacılık ve uzay sanayinde, elektrik santrali türbinlerinde ve gaz türbini motorlarında geniş bir alanda kullanılmaktadır [Soboyejo ve Srivatsan, 2007]. Inconel 718 ve Ti-6Al-4V, süper alaşımlar olarak nitelendirilmekte, yüksek mukavemetli olmaları ve sıcaklık ile aşınmaya karşı dirençleri nedeniyle işlenmesi zor malzemeler olarak kabul edilmektedir.

İlgili literatür çalışmalarında, Ekmekçi (2007) tarafından elektriksel erozyonla işlenmiş (EEI) yüzeylerde dielektrik sıvı ve elektrot türünün beyaz katman kalınlığına etkisi, X-1şını kırınım metodu kullanılarak kalıntı östenit ve kalıntı gerilmeler açısından incelenmiştir. Deneyler, aynı çalışma koşullarında iki farklı tip elektrot (bakır ve grafit) ve dielektrik sıvı (gazyağı ve deiyonize su) kullanılarak gerçekleştirilmiştir. Mevcut çalışma, dielektrik sıvı olarak gazyağı kullanıldığında elektrot tipinden bağımsız olarak iş parçası yüzeyinin karbonla doymuş olduğunu göstermektedir. Ghanem vd. (2003) ise çelik tiplerinin EEİ yöntemin yüzey bütünlüğüne olan etkisini araştırmışlardır. Deneyler iki sertleştirilebilir çelik ve iki sertleştirilemeyen çelik ile gerçekleştirilmiştir. Yüzey bütünlüğ̈̈; pürüzlülük, mikro sertlik, kalıntı gerilme dağılımı ve yakın yüzey hasarı ile karakterize edilmiştir. Bu araştırmalarda, elde edilen yüzey profillerinin yüzeye yakın tabakalarda daha düzensiz, daha derin tabakalarda ise oldukça düzenli olduğu; ayrıca deneysel olarak elde edilen kalıntı gerilme değerlerinin hesaplanan kalıntı gerilme değerlerinden daha düşük olduğu görülmüştür. Keskin vd. (2006) tarafindan yapılan araştırmalarda, yüzey pürüzlülügünü etkileyen parametreleri belirlemek için deneyler gerçekleştirilmiş ve çeliğin elektro deşarj ile işlenmesinde bakır elektrot kullanılmıştır. Güç, vurum süresi ve kıvılcım süresi parametrelerinin yüzey pürüzlülüğüne etkisini belirlemek için bir denklem elde edilmiştir. Maji ve Pratihar (2010); akım, vurum süresi ve darbe boşluk oranını üç giriş parametresi, malzeme kaldırma oranı (MRR) ve yüzey pürüzlülüğünü ise (SR) ise çıkış parametresi olarak kullanılarak regresyon modelleme yapmışlardır. Her model için regresyon katsayısı belirlenmiştir. Maksimum MRR ve minimum SR'1 sağlamak için bir algoritma kullanılarak sorun çözülmüştür. Zhang vd. (2011) elektro erozyon ile işlemede, iş parçası yüzeyinde yeniden katılaşmış tabaka oluşumunu incelemişlerdir. Yeniden katılaşmış tabaka özellikleri, dielektrik sıvının türü ile büyük bir ilişkiye sahiptir. Bu araştırmada yağ içinde su (W/O) emülsiyonu dielektrik olarak kullanılmıştır. Taramalı elektron mikroskobu (SEM), X-ışını kırınım (XRD), enerji dağıtıcı spektrografi (EDS) ve mikro sertlik analizi yapılmıştır. W/O emülsiyonu ile gazyağı ve deiyonize suyu karşılaştırılmıştır. Araştırmalara göre W/O emülsiyonunda, gazyağı ve deiyonize suya göre ergiyip katılaşmış tabaka, daha yüksek, yüzey pürüzlülük, kalınlık ve mikro sertliğe sahiptir. Kanlayasiri ve Boonmung (2007), EEİ ile çelik kalıbı üretiminde işleme parametrelerinin DC53 çeliğin yüzey pürüzlülüğü üzerindeki etkilerini araştırmışlardır. Vurum süresi, bekleme süresi, akım darbesi ve tel gerginliği incelenmiştir. Yüzey pürüzlülüğünü etkileyen parametreleri bulmak için varyans analizi (ANOVA) kullanılmıştır. ANOVA sonuçlarına göre, vurum süresi ve akım darbesi DC53 çeliğin yüzey pürüzlülüğü üzerinde önemli etkisi vardır. Yüzey pürüzlülüğü bu iki değişken arttıkça artmıştır. Son olarak, çoklu regresyon yöntemi kullanılarak vurum süresi ve akım darbesin yüzey pürüzlülüğüne etkisi bir matematiksel denklem ile ifade edilmiştir. Oğuzhan Yılmaz vd. (2009) uzay ve havacılık sanayisinde Ti-6Al-4V ve Inconel 718 malzeme ve 2 tür elektrot malzemesi (pirinç ve bakır) kullanarak elektriksel erozyon ile işleme ile ilgili incelemeler yapmışlardır. Pirinç elektrotta her iki iş parçası için için bakır elektroda göre daha yüksek işleme hızı değerleri görülmüştür. Elektrot Aşınma Oranları (EAO) karşılaştırıldığında ise pirinç elektrot bakır elektroda göre Inconel $718^{\prime}$ de daha az ve Ti-6Al$4 \mathrm{~V}$ 'da yüksek EAO değerine sahiptir.

Bu çalışmada, uzay ve havacılık alaşımlarının elektriksel erozyonla işlemi (EEI) sonrasında oluşan yüzey bütünlüğü incelenmiştir. Çalışma kapsamında, EEİ yöntemi kullanılarak, Ti-6Al-4V ve Inconel 718 süper alaşım malzemelerinde delikler işlenerek delik yüzeylerinin yüzey bütünlükleri detaylı bir şekilde incelenmiştir. Okka (2011) tarafından yapılan tez çalışmasında gerçekleştirilen deneyler sonunda elde edilen en uygun EEİ parametre seti (boşalım akımı, vurum süresi, bekleme süresi ve kapasitans) kullanılarak delikler delinmiştir. İşlenen deliklerin formu, mikro yapısı, yüzey pürüzlükleri ve topografyası, yüzey çatlakları gibi yüzey bütünlüğü unsurları EEİ ile delik delme işlemlerinin yüzey üzerinde bıraktıkları etkilerin ortaya çıkarılması için incelenmiştir.

\section{II.MATERYAL VE METOD}

\section{1. Deney Numuneleri}

Deneylerde iş parçası olarak Ti-6Al-4V ve Inconel 718 malzemesi kullanılmıştır. Deney numuneleri 6x11x35 mm ebatlarında hazırlanmıştır (Şekil 1). Bu çalışmada iki farklı elektrot malzemesi (prinç ve bakır) silindirik formunda tek 
delikli ve boyları $400 \mathrm{~mm}$ ve dış çapları $0.5 \mathrm{~mm}, 1.5 \mathrm{~mm}$, $2 \mathrm{~mm}, 2.5 \mathrm{~mm}$ ve $3 \mathrm{~mm}$ olarak kullanılmıştır.

Yapılan ön deneyler ve literatürde kullanılan değerler esas alınarak boşalım akımı 12.5A, dielektrik sıvı basıncı 100 bar, elektrot dönüş devir sayısı $100 \mathrm{dev} / \mathrm{dak}$, vurum süresi $25 \mu$ s ve bekleme süresi $12.5 \mu$ s olarak belirlenmiştir. [Okka,2011]. Mikrosertlik değerleri, numunenin boyuna belli aralıklarla yapılan ölçümler ile tespit edilmiştir. Ti$6 \mathrm{Al}-4 \mathrm{~V}$ ve Inconel 718 malzemenin kimyasal bileşimleri Tablo 1 ve 2 'de gösterilmektedir.
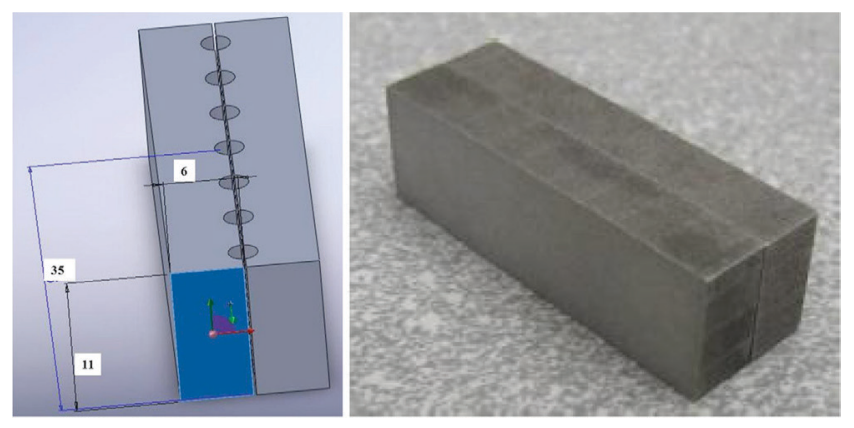

Şekil 1. 6x11x35 mm ebatlarındaki iş parçaları

Tablo 1. Ti-6Al-4V alaşımının kimyasal bileşimi [Okka, 2011]

\begin{tabular}{rrrrrrr}
\hline & $\mathrm{C}$ & $\mathrm{Al}$ & $\mathrm{V}$ & $\mathrm{O}$ & $\mathrm{Fe}$ & $\mathrm{Ti}$ \\
\hline$(\%)$ & 0.012 & 6.07 & 4.2 & 0.149 & 0.03 & Balans \\
\hline
\end{tabular}

Tablo 2. Inconel 718 alaşımının kimyasal bileşimi [Okka, 2011]

\begin{tabular}{lllllllll}
\hline & $\mathrm{Fe}$ & $\mathrm{Ni}$ & $\mathrm{Cr}$ & $\mathrm{Mo}$ & $\mathrm{Nb}$ & $\mathrm{Ti}$ & $\mathrm{Al}$ & $\mathrm{C}$ \\
\hline Min & Balans & 50 & 17 & 2.8 & 4.75 & 0.65 & 0.2 & \\
\hline Max & 55 & 21 & 3.3 & 5.5 & 1.15 & 0.8 & 0.08 \\
\hline
\end{tabular}

Deneylerde silindirik formunda tek delikli iki farklı elektrot malzemesi (pirinç ve bakır) kullanılmıştır. Bu elektrotlar elektriksel erozyon yönteminde hassas takım olarak kullanılmaktadır. Deneylerde kullanılacak elektrot malzemelerinin başlıca özellikleri Tablo 3 'te verilmiştir. Deneyler, boyu $400 \mathrm{~mm}$ ve dış çapları $0.5 \mathrm{~mm}, 1.5 \mathrm{~mm}, 2 \mathrm{~mm}, 2.5 \mathrm{~mm}$ ve $3 \mathrm{~mm}$ elektrotlar kullanılarak gerçekleştirilmiştir.

Tablo 3. Elektro erozyonda kullanılan elektrotların özellikleri

\begin{tabular}{lll}
\hline Elektrot malzemesi & Bakır & Pirinç \\
\hline Erime noktas $\left({ }^{\circ} \mathrm{C}\right)$ & 1084 & $900-940$ \\
Elektriksel direnç $(\mathrm{ohm}-\mathrm{cm})$ & 1.69 & 4.7 \\
Is1l iletkenlik $\left(\mathrm{W} / \mathrm{m}-{ }^{\circ} \mathrm{K}\right)$ & 391 & 159 \\
Özgül 1s1 kapasitesi $\left(\mathrm{J} / \mathrm{g}^{\circ} \mathrm{C}\right)$ & 0.385 & 0.380 \\
\hline
\end{tabular}

\section{III.DENEYLER}

Deneysel çalışmalar sonucunda elde edilen deliklerin yüzey bütünlügü analizleri kapsamında sırasıyla giriş ve çıkış çap ölçümleri, beyaz katman kalınlık ölçümleri, mikro yapı analizleri, SEM analizleri, EDS analizleri ve yüzey pürüzlülük ölçümleri gerçekleştirilmiş ve sonuçlar üzerinden değerlendirmelerde bulunulmuştur.

\subsection{Delik Giriş ve Çıkış Çap Ölçümleri}

Silindirik tek delikli elektrotlar kullanılarak gerçekleştirilen EEİ ile delik delme işlemlerinde, iş parçasında oluşturulmak istenilen çap büyüklüğü önem arz etmektedir. Şekil 2 ve Şekil 3’te pirinç elektrot ile delinmiş deliklerin elektrotun iş parçasına giriş kısmından alınan mikroskop görüntüleri, Şekil 4 ve Şekil 5 'te ise bakır elektrot ile alaşım malzemelerinde delinen deliklerin giriş çapları gösterilmiştir. Giriş çap büyümesi genellikle elektrot çapının \%10 fazlası şeklindedir. EEİ prensibinde, elektroda gelen doğru akım enerjisinin iş parçasına doğru deşarj olması beklenir. Bu esnada, elektrodun elektriksel iletkenliği, akımın geçişine karşı göstermiş olduğu direnç ve termal iletkenlik değerleri önem arz etmektedir. Dolayısıyla, küçük çaplı her iki elektrot malzemesi (Bakır ve Pirinç) için, ağırlık, hacim ve yüzey alanlarının küçük olmasından dolayı, akım geçişlerine karşı düşük direnç göstererek akımın büyük oranda deşarj enerjisine (büyük aralıklı kıvılcımlara) dönüştüğü söylenebilir. Sonuçta, küçük elektrot çaplarında daha fazla çap büyümesi ile karşllaşılmıştır. Tablo 4, 5, 6 ve 7 'de verilen değerler dikkate alındığında, her çaptaki elektrot ile delinen deliklerde giriş ve çıkış delik çaplarında büyüme görülmektedir.
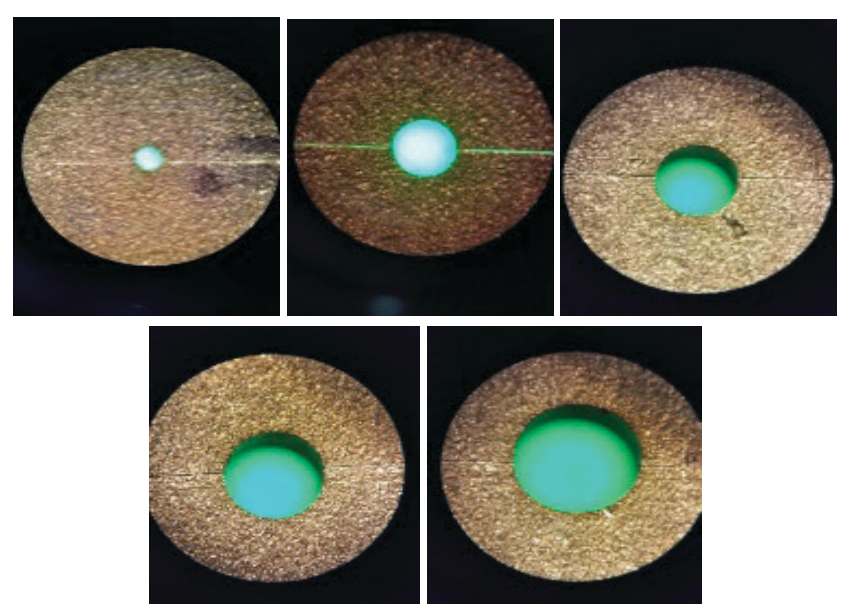

Şekil 2. Pirinç elektrot ile Inconel 718 iş parçalarında sırayla (0.51.5-2-2.5-3mm) deliklerinin giriş çap gösterimi 

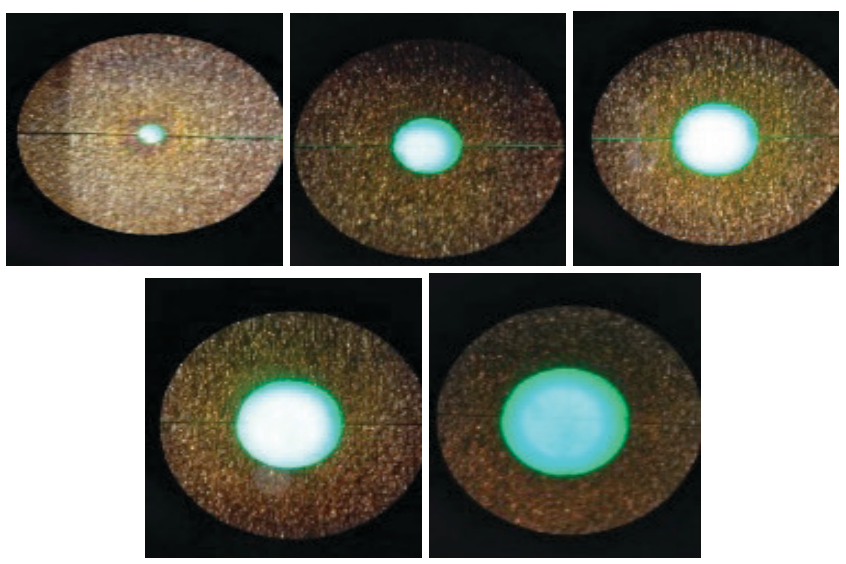

Şekil 3. Pirinç elektrot ile Ti-6Al-4V iş parçalarında sırayla (0.51.5-2-2.5-3mm) deliklerinin giriş çap gösterimi
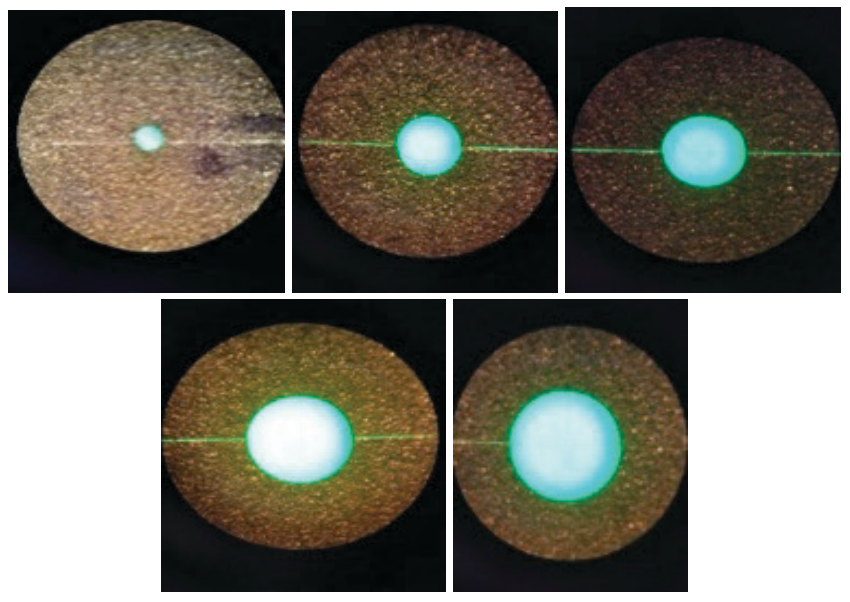

Şekil 4. Bakır elektrot ile Inconel 718 iş parçalarında sırayla (0.51.5-2-2.5-3mm) deliklerinin giriş çap gösterimi
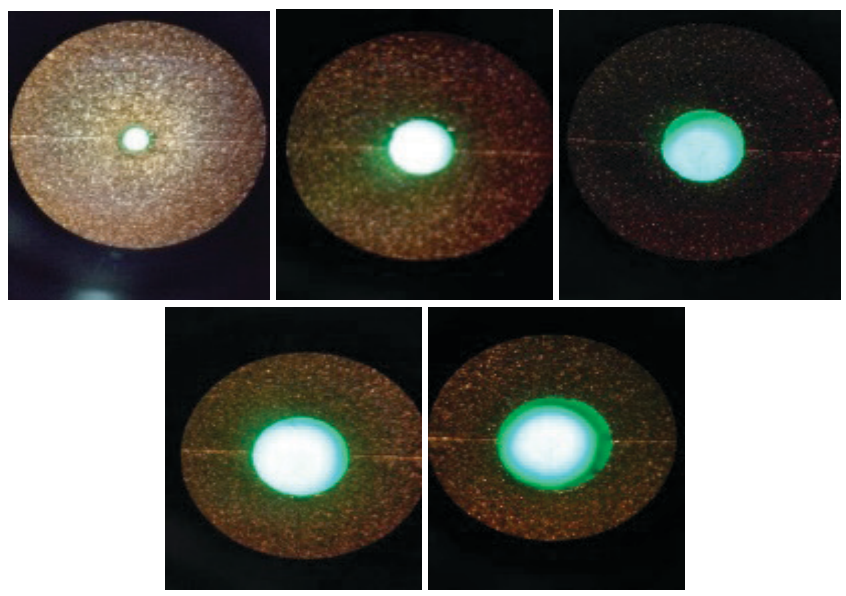

Şekil 5. Marmara fen bil. dergisi. Bakır elektrod ile Ti-6Al-4V iş parçalarında sırayla $(0.5-1.5-2-2.5-3 \mathrm{~mm})$ deliklerinin giriş çap gösterimi
Tablo 4. Pirinç elektrot ile Inconel 718 iş parçası deliklerinin çap ölçümleri

\begin{tabular}{llll}
\hline $\begin{array}{l}\text { Pirinç elektrot } \\
\text { çapı }(\mathbf{m m})\end{array}$ & $\begin{array}{l}\text { Deliğin giriş } \\
\text { çapı }(\mathbf{m m})\end{array}$ & $\begin{array}{l}\text { Deliğin çıkış } \\
\text { çapı }(\mathbf{m m})\end{array}$ & $\begin{array}{l}\text { \% Deliğin giriş çap } \\
\text { büyümesi }\end{array}$ \\
\hline 0,5 & 0,64 & 0,60 & 28,0 \\
1,5 & 1,64 & 1,60 & 9,3 \\
2,0 & 2,18 & 2,10 & 9,0 \\
2,5 & 2,63 & 2,58 & 5,2 \\
3,0 & 3,14 & 3,05 & 4,7 \\
\hline
\end{tabular}

Tablo 5. Pirinç elektrot ile Ti-6Al-4V iş parçası deliklerinin çap ölçümleri

\begin{tabular}{llll}
\hline $\begin{array}{l}\text { Pirinç elektrot } \\
\text { çapı }(\mathbf{m m})\end{array}$ & $\begin{array}{l}\text { Deliğin girişs } \\
\text { çapı }(\mathbf{m m})\end{array}$ & $\begin{array}{l}\text { Deliğin çıkış } \\
\text { çapı }(\mathbf{m m})\end{array}$ & $\begin{array}{l}\text { \% Deliğin giriş } \\
\text { çap büyümesi }\end{array}$ \\
\hline 0,5 & 0,63 & 0,62 & 26,0 \\
1,5 & 1,76 & 1,62 & 17,3 \\
2,0 & 2,31 & 2,17 & 15,5 \\
2,5 & 2,64 & 2,57 & 5,6 \\
3,0 & 3,15 & 3,06 & 5,0 \\
\hline
\end{tabular}

Tablo 6. Bakır elektrot ile Inconel 718 iş parçası deliklerinin çap ölçümleri

\begin{tabular}{llll}
\hline $\begin{array}{l}\text { Pirinç elektrot } \\
\text { çapı }(\mathbf{m m})\end{array}$ & $\begin{array}{l}\text { Deliğin giriş } \\
\text { çapı }(\mathbf{m m})\end{array}$ & $\begin{array}{l}\text { Deliğin çıkış } \\
\text { çapı }(\mathbf{m m})\end{array}$ & $\begin{array}{l}\text { \% Deliğin giriş çap } \\
\text { büyümesi }\end{array}$ \\
\hline 0,5 & 0,68 & 0,57 & 36,0 \\
1,5 & 1,70 & 1,63 & 13,3 \\
2,0 & 2,17 & 2,14 & 8,5 \\
2,5 & 2,67 & 2,60 & 6,8 \\
3,0 & 3,22 & 3,12 & 7,3 \\
\hline
\end{tabular}

Tablo 7. Bakır elektrot ile Ti-6Al-4V iş parçası deliklerinin çap

\begin{tabular}{llll}
\multicolumn{4}{c}{ ölçüleri } \\
\hline $\begin{array}{l}\text { Pirinç elektrot } \\
\text { çapı (mm) }\end{array}$ & $\begin{array}{l}\text { Deliğin giriş } \\
\text { çapı (mm) }\end{array}$ & $\begin{array}{l}\text { Deliğin çııış } \\
\text { çapı (mm) }\end{array}$ & $\begin{array}{l}\text { \% Deliğin giriş çap } \\
\text { büyümesi }\end{array}$ \\
\hline 0,5 & 0,67 & 0,60 & 34,0 \\
1,5 & 1,64 & 1,60 & 9,3 \\
2,0 & 2,18 & 2,10 & 9,0 \\
2,5 & 2,66 & 2,58 & 6,4 \\
3,0 & 3,10 & 3,00 & 3,3 \\
\hline
\end{tabular}

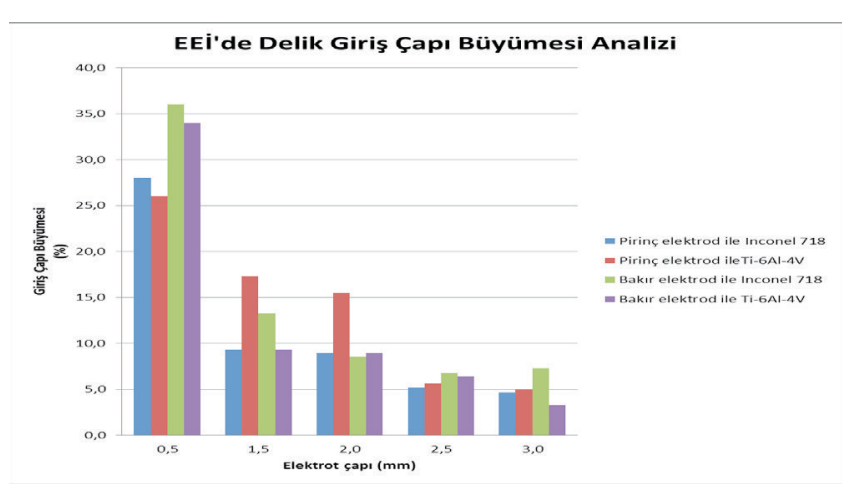

Şekil 6. Pirinç ve bakır ile delinen deliklerde yüzdelik çap büyümesi 


\section{2. Mikroyapı ve Ortalama Ergimiş Katılaşmış Tabaka Kalınlığı İncelemeleri}

Mikroyapı ve yeniden katılaşmış tabaka incelemeleri için ilk aşamada tüm malzemelerin yüzeyleri, 240, 400, 600, 800, 1000 ve 1200 boyutlu zımpara kâğıtları ile mekanik olarak parlatılmıştır. Mekanik parlatma işlemlerinden sonra, numunelerin yüzeyleri kimyasal aşındırma işlemi ile dağlanmıştır. Dağlama işleminde, Ti-6Al-4V için $92 \mathrm{ml}$ saf su, $6 \mathrm{ml}$ nitrik asit, $2 \mathrm{ml}$ Hidroflorik asit ve Inconel 718 için 45 gram Demir klorür, 9 gram Bakır amonyum klorür, $150 \mathrm{ml}$ Hidroklorik asit ve $75 \mathrm{ml}$ saf su kullanılmıştır. Dağlama işlemi her iki malzeme için yaklaşık olarak 20 25 saniye süre ile parça yüzeylerine uygulanmıştır ve sonrasında bu yüzeyler su ve alkol ile temizlenmiştir. Dağlama işleminden sonra, numuneler bir Leica DM 2500 M optik mikroskop kullanılarak 10x ve 20x büyütmede görüntülenmiştir. Pirinç ve bakır elektrotlar ile delinen deliklerden alınan görüntüler (Şekil 7, Şekil 8, Şekil 9, Şekil 10) üzerinde yapılan yeniden katılaşmış tabaka kalınlığı ölçümlerinde (Tablo 6), pirinç ve bakır elektrotların farklı tabaka kalınlıkları oluşturduğu gözlemlenmiştir. Benzer durum farklı iş parçası malzemeleri için de geçerlidir. Örneğin, yeniden katılaşmış tabaka kalınlığı prinç elektrot ile Ti-6Al-4V işlemede 6.9 ila $66.2 \mu \mathrm{m}$ arasında olurken; bakır elektrot ile Ti6Al-4V işlemede 4.9 ila $55.1 \mu \mathrm{m}$ arasında değişmiştir. Ayrıca Pirinç elektrot ile Inconel 718 işlemede 16.5 ila $99.4 \mu \mathrm{m}$ tabaka kalınlığı elde edilirken, bu değerlerin bakır elektrot ile Inconel 718 işleminde 3.9 ila $74.3 \mu \mathrm{m}$ değerleri arasına düştüğü görülmüştür. Şekillerde görüldüğü gibi, en yüksek tabaka kalınlığı Inconel 718'de ve Ti-6Al-4V alaşımlarında prinç elektrotla oluşmuştur.

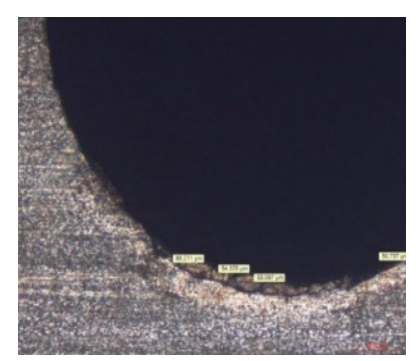

(a)

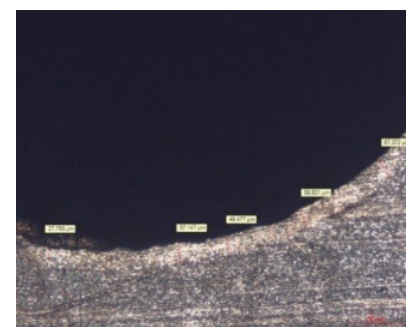

(c)

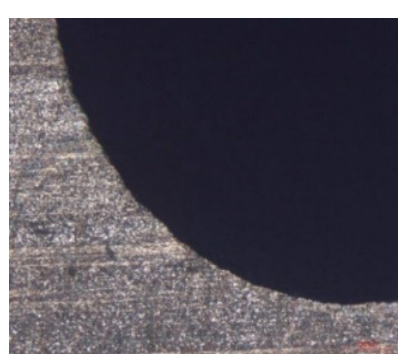

(b)

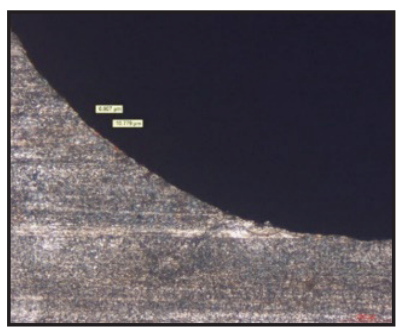

(d)
Şekil 7. Pirinç elektrot ile delinmiş Ti-6Al-4V malzemede oluşan beyaz katman (a) $1.5 \mathrm{~mm}$ çap ile delme (b) $2 \mathrm{~mm}$ çap ile delme (c) $2.5 \mathrm{~mm}$ çap ile delme (d) $3 \mathrm{~mm}$ çap ile delme

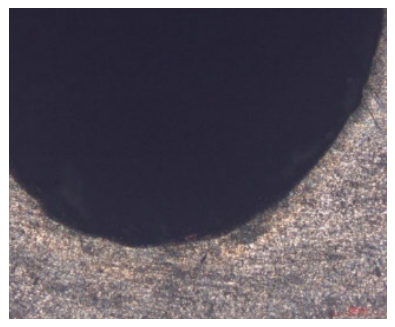

(a)

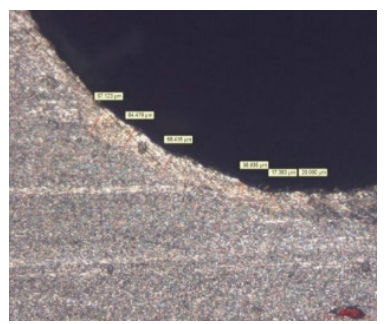

(c)

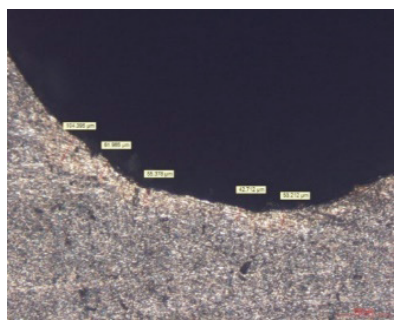

(b)

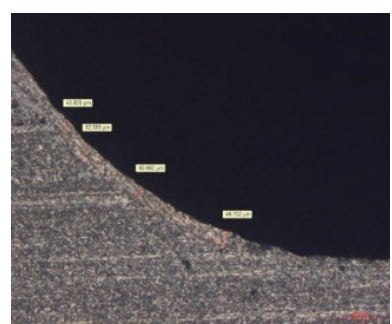

(d)
Şekil 8. Bakır elektrot ile delinmiş Ti-6Al-4V malzemede oluşan beyaz katman(a) $1.5 \mathrm{~mm}$ çap ile delme (b) $2 \mathrm{~mm}$ çap ile delme (c) $2.5 \mathrm{~mm}$ çap ile delme (d) $3 \mathrm{~mm}$ çap ile delme

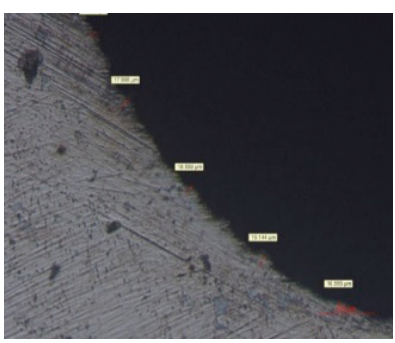

(a)

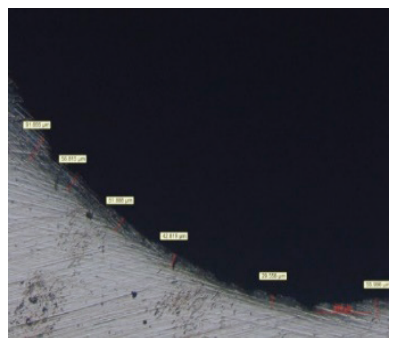

(c)

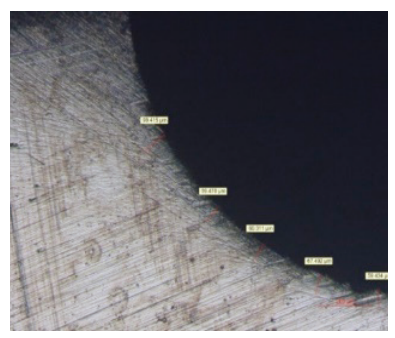

(b)

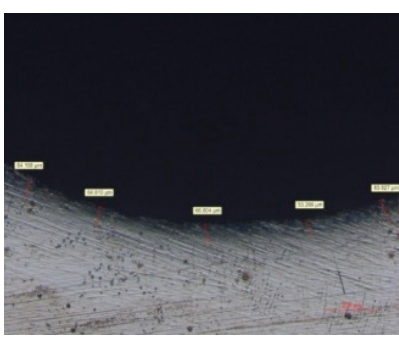

(d)
Şekil 9. Prinç elektrot ile delinmiş Inconel 718 malzemede oluşan beyaz katman (a) $1.5 \mathrm{~mm}$ çap ile delme (b) $2 \mathrm{~mm}$ çap ile delme (c) $2.5 \mathrm{~mm}$ çap ile delme (d) $3 \mathrm{~mm}$ çap ile delme 


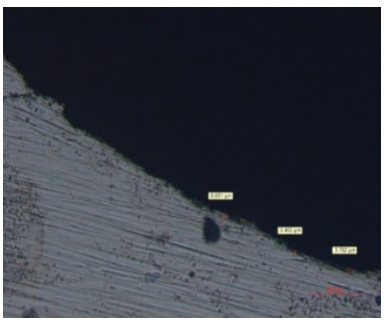

(a)

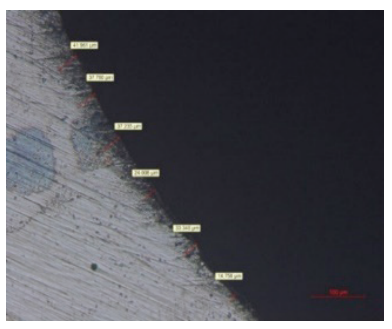

(c)

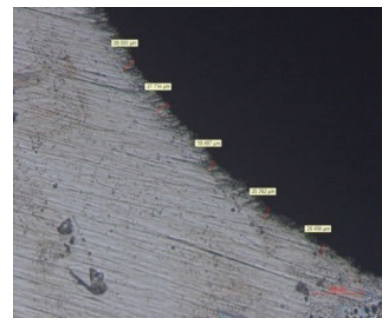

(b)

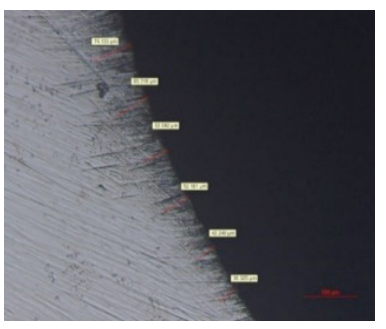

(d)
Şekil 10. Bakır elektrot ile delinmiş Inconel 718 malzemede oluşan beyaz katman (a) $1.5 \mathrm{~mm}$ çap ile delme (b) $2 \mathrm{~mm}$ çap ile delme (c) $2.5 \mathrm{~mm}$ çap ile delme (d) $3 \mathrm{~mm}$ çap ile delme

Tablo 6. EEİ sonrasında ölçülen ortalama yeniden katılaşmış tabaka kalınlıkları

\begin{tabular}{lll}
\hline \multicolumn{1}{c}{ Deney } & \multicolumn{2}{c}{ Ortalama beyaz tabaka kalınlığı $(\mu \mathbf{m})$} \\
\hline Inconel 718 & Bakır Elektrot & Prinç Elektrot \\
\hline 1.5 & $3.9-6.6$ & $16.5-17.9$ \\
2 & $19.4-28.5$ & $59.4-99.4$ \\
2.5 & $14.5-41.9$ & $29.6-91.6$ \\
3 & $36.3-74.3$ & $53.2-64.1$ \\
\hline Ti-6Al-4V & Bakır Elektrot & Pirinç Elektrot \\
\hline 1.5 & & $50.7-66.2$ \\
2 & $42.7-44.3$ & $27.7-67$ \\
2.5 & $17.3-55.1$ & $6.9-20$ \\
3 & $4.9-15$ & \\
\hline
\end{tabular}

Yüzeyde oluşan yeniden katılaşmış tabaka oldukça sert ve kırılgan bir yapıya sahiptir. Yeniden katılaşmış tabakanın çok kalın olması çatlamaya, yüzey gerilmelerinin artmasına ve sonunda parçanın kısa sürede hasara uğramasına sebep olmaktadır. Dolayısıyla, EEİ sonucunda yeniden katılaşmış tabaka kalınlığının ince olması istenmektedir. Yeniden katılaşmış tabaka kalınlığı, çalışma akımına bağlı olarak doğrusal bir eğimle artmaktadır.

\section{3. Yüzey Yapısı}

Deneysel çalışmalarla elde edilen deliklerin yüzey bütünlüğü analizlerinde, SEM görüntüleri, 1sının yüzeylerde bıraktığ 1 etkilerin gözlemlenmesi açısından önem arz etmektedir. SEM görüntülerinde, EEİ işlemlerinde oluşan kıvılcımların oluşturduğu kraterler, yüzey topografyaları, mikro çatlaklar, kalıntılar vb etkiler incelenebilmektedir. Yüzey; malzemeden kaldırılan ve sıvı basıncı ile ara bölgeden uzaklaştırılamayan küresel taneciklerden, eriyerek yüzeye damla şeklinde yapışan döküntülerden, çatlak, kalıntı ve farklı ebatlarda gelişi güzel dağılmış kraterlerden oluşmaktadır. Her bir kıvılcım ile iş parçasının yüzeyinde bir krater oluşurken, elektrot yüzeyinden de küçük bir miktar malzeme aşındırır. Dolayısıyla, elektro erozyon ile işlenmiş yüzeylerin yönsüz bir yüzey profiline sahip olduğu söylenebilir. Inconel $718^{\prime}$ in ergime sicaklığ $1363^{\circ} \mathrm{C}$ ve Ti-6Al-4V alaşımının ergime sıcaklığ ${ }_{1}$ ise $1649^{\circ} \mathrm{C}$ 'dir. Şekil 11ve Şekil 14 arasındaki SEM fotoğrafları incelendiğinde, düşük ergime sıcaklığına sahip olduğundan, işlenmiş Inconel 718 iş parça yüzeyinin daha kolay ergiyip buharlaştığ görülmüştür. Bunun ile birlikte Ti-6Al-4V alaşımının 1sı iletkenliği $\left(6.7 \mathrm{~W} / \mathrm{m}-{ }^{\circ} \mathrm{K}\right)$ Inconel 718 alaşımına göre $\left(11.4 \mathrm{~W} / \mathrm{m}-{ }^{\circ} \mathrm{K}\right)$ daha düşüktür dolayısıyla Ti6Al4V alaşımdaki oluşan yüzey çatlakları daha yoğundur.

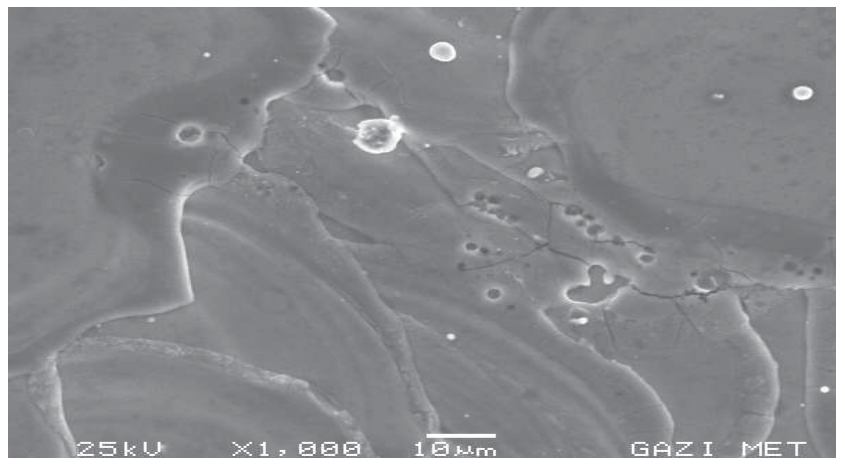

Şekil 11. Bakır elektrot (2mm çap) ile delinmiş Inconel 718'ın SEM fotoğrafları (x1000)

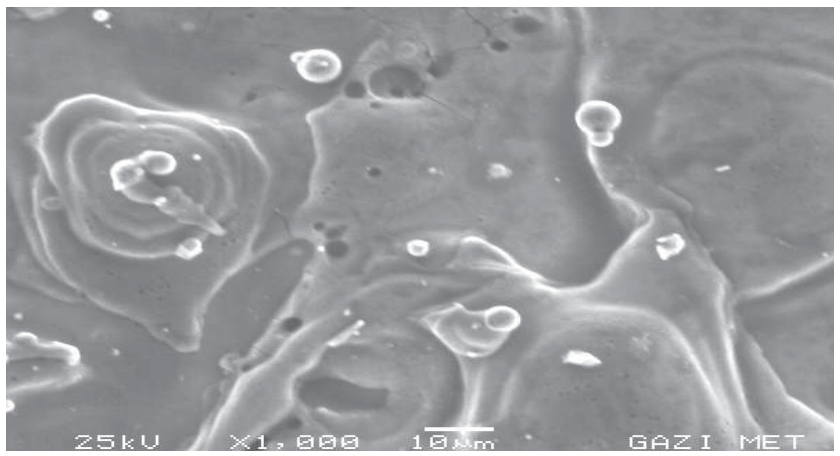

Şekil 12. Pirinç elektrot (2mm çap) ile delinmiş Inconel 718'ın SEM fotoğrafları (x1000) 


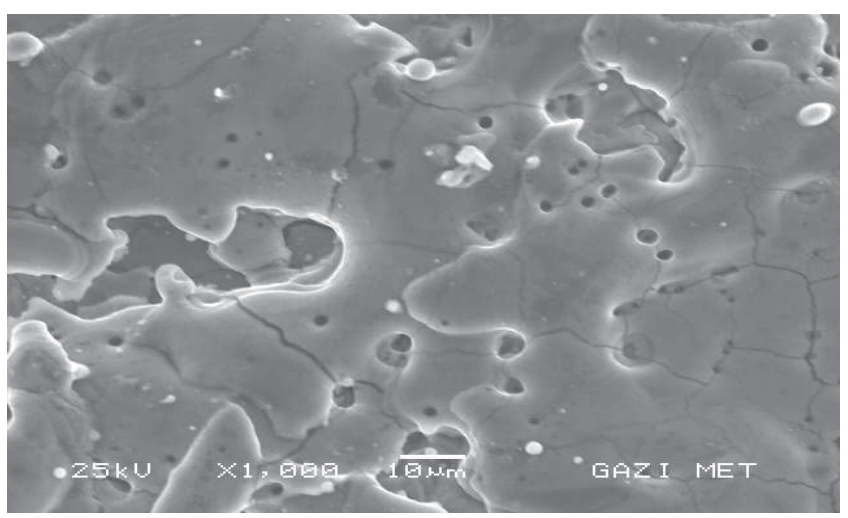

Şekil 13. Bakır elektrot (2mm çap) ile delinmiş Ti-6Al-4V'ın SEM fotoğrafları (x1000)

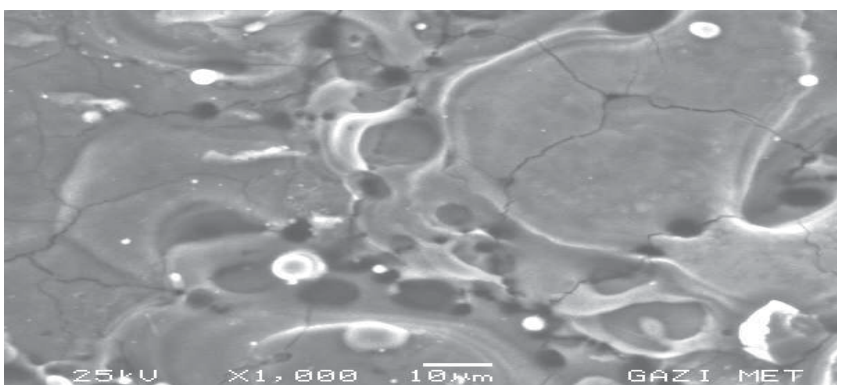

Şekil 14. Pirinç elektrot (2mm çap) ile delinmiş Ti-6Al-4V'ın SEM fotoğrafları (x1000)

SEM görüntüleri bakır yerine pirinç elektrot kullanıldığında hem Ti-6Al-4V ve hem de Inconel 718 iş parçaları üzerinde daha iyi yüzey bütünlüğünün elde edildiğini göstermiştir. Bunun nedeninin Pirincin 1sıl iletkenliğinin bakıra göre daha düşük olması olduğu söylenebilir. Dolayısıyla, pirinç elektrot deşarj esasında oluşan yoğun 1sı enerjisini absorbe edemez ve bu enerji daha çok iş parçası tarafindan absorbe edilir.

\section{4. EDS Sonuçları}

Analiz sonuçlarına göre, işlenmiş yüzeylerin, ağırlıklı olarak iş parçası malzemesi ve bir miktar da elektrot malzemesinden oluştuğu görülmektedir. Şekil 15 'te farklı elektrotlarla işlenmiş yüzeylerden alınan EDS analiz sonuçlarına yer verilmiştir. Yüksek sıcaklığın, bir miktar elektrot malzemesinin de iş parçası yüzeyine yapışmasına neden olduğu ortaya çıkmıştır. Analizi yapılan elementler Inconel 718'de Fe,Ni,Cr,Nb ve Ti-6Al-4V'da Al,V,Ti elementleridir. Grafikler incelendiğinde; Inconel 718 alaşımının delinmesinde bakır elektrot yerine pirinç elektrot kullanıldığında elementel kayıp daha fazla olmaktadır. Ti-6Al-4V alaşımının delinmesinde pirinç elektrot yerine bakır elektrot kullanıldığında elementel kayıp daha fazla olmaktadır. EDS analiz sonuçlarına göre her iki elektrot malzemesi ile işlenmiş Ti-6Al-4V yüzeylerinde $\mathrm{Al}$ ve $\mathrm{V}$ oranında düşüş gözlenmiştir. Bu elementlerin 1sıl etki nedeniyle buharlaştı̆̆ 1 ve dielektrik sıvı ile uzaklaştırıldığı söylenebilir. Ancak Inconel 718 'de her iki elektrot malzemesi ile gerçekleştirilen elektro erozyon işlemeden sonra $\mathrm{Fe}, \mathrm{Ni}, \mathrm{Cr}$ ve $\mathrm{Nb}$ elementlerinin oranlarında yükselme gözlenmiştir. Her ne kadar bu tür elementlerle ilgili bir katkı durumu olmasa da, ölçüm yapılan bölgelerdeki kalıntıların yoğunluğu bu sonucun oluşmasına sebep olduğu düşünülmektedir.

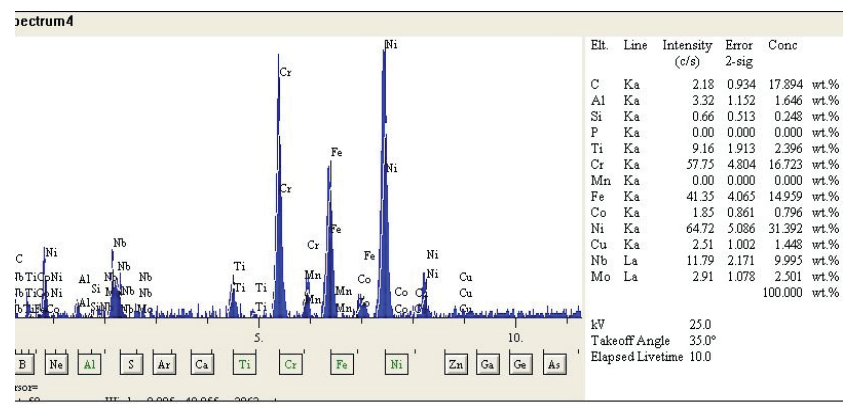

Şekil 15. EDS analiz görüntüsü (x500)

\subsection{Yüzey Pürüzlülüğü Sonuçları}

Elektriksel erozyon işleminden sonra delinmiş yüzeylerin kalitesini değerlendirebilmek için yüzey pürüzlülüğü ölçümleri gereklidir. Bu çalışmada delinmiş deliklerin yüzey pürüzlülüğünü ölçmek için Mitutoyo SJ 410 cihazı kullanılmıştır. Ölçüm için kalem tipi temaslı yüzey pürüzlülüğü cihazı (prob) kullanılmıştır. Yüzey pürüzlülük ölçümleri 1.5, 2.5 ve $3 \mathrm{~mm}$ çapındaki deliklerde gerçekleştirilmiştir. Yapılan deneyler neticesinde elde edilen yüzey pürüzlülük değerleri Tablo 7'de verilmiştir. Bu çalışmada, iki farklı tip elektrot (Bakır ve Pirinç) kullanılarak iki farklı malzeme üzerinden (Ti-6Al-4V ve Inconel 718) imal edilmiş deliklerin yüzey pürüzlülükleri karşılaştırılmıştır. Tablo 7'deki sonuçlara göre Ti-6Al-4V iş parçasın üzerinde delinen deliklerin daha yüksek yüzey pürüzlülük değerlerine sahip oldukları görülmektedir. Bu durum Ra, Rq ve Rz değerleri için de geçerlidir. Inconel 718 alaşımında elde edilen yüzey pürüzlülükleri göreceli olarak daha düşük çıkmıştır. Ayrıca, Ti6Al-4V alaşımının EEİ işlemi esnasında elektrotla kimyasal reaksiyona girme eğilimi göstermesi ve işleme esnasında ergiyen malzemenin elektrota yapışması kıvılcımların kararsız biçimde gelişmesine neden olmaktadır. Sonuç olarak, işlenen yüzeyin kalitesi bozulmakta ve yüzey pürüzlülük 
değerleri artmaktadır. Ti-6Al-4V alaşımının delinmesinde pirinç elektrot kullanıldığında 1.5 ve $2.5 \mathrm{~mm}$ çaplardaki deliklerde daha kaba yüzey oluştuğu görülmüştür.

Tablo 7. Yüzey pürüzlülük ölçümleri

\begin{tabular}{llll}
\hline Elektrot çapı $(\mathbf{m m})$ & $\mathbf{R a}(\boldsymbol{\mu m})$ & $\mathbf{R q}(\boldsymbol{\mu m})$ & $\mathbf{R z}(\boldsymbol{\mu m})$ \\
\hline Bakır ile delinmiş Ti-6Al-4V & & & \\
\hline 1.5 & 3.040 & 3.909 & 20.457 \\
2.5 & 2.953 & 3.808 & 20.053 \\
3 & 4.147 & 5.205 & 24.312 \\
\hline Bakır ile delinmiş Inconel 718 & & & \\
\hline 1.5 & 2.067 & 2.699 & 15.266 \\
2.5 & 1.950 & 2.543 & 13.882 \\
3 & 2.040 & 2.702 & 18.297 \\
\hline Pirinç ile delinmiş Ti-6Al-4V & & & \\
\hline 1.5 & 3.634 & 4.528 & 22.284 \\
2.5 & 3.484 & 4.371 & 20.840 \\
3 & 3.831 & 4.813 & 24.519 \\
\hline Pirinç ile delinmiş Inconel 718 & & & \\
\hline 1.5 & 2.609 & 3.215 & 15.276 \\
2.5 & 2.065 & 2.693 & 3.215 \\
3 & 3.205 & 4.041 & 15.276 \\
\hline
\end{tabular}

\section{IV.BULGULAR VE TARTIŞMA}

Bu çalışma kapsamında iki farklı metal alaşımı(Ti-6Al-4V ve Inconel 718) ve iki farklı elektrot malzemesi (Bakır ve Pirinç) kullanılmıştır.. Deneyler sonucunda, EEİ ile delik delme işlemleri için yüzey bütünlüğü analizleri (mikroskop görüntüleri, beyaz katman kalınlık ölçümleri, SEM ve EDS analizleri, yüzey pürüzlülük ölçümleri) gerçekleştirilmiştir. Yapılan incelemeler sonucunda aşağıdaki bulgular ortaya çıkmıştı:

- Pirinç elektrot kullanıldığında her iki alaşım malzemesinde de daha düşük giriş çapı büyüme oranına sahip delikler delinmektedir. Delik delmede pirinç elektrot kullanımının Inconel 718 ve Ti-6Al-4V alaşımlarında daha düşük giriş çapı büyüme oranına sahip deliklerin delinebilmesi beklenebilir.

- Beyaz katman kalınlığı, bakır elektrot kullanıldığında pirinç elektrot kullanımına göre daha incedir. Çok sert ve kırılgan olan bu katmanın ince olması istenen bir özelliktir. Bu nedenle, her iki alaşım için ince beyaz katman kalınlıklarının elde edilmesi için bakır elektrot tercih edilmelidir.

- SEM görüntülerine göre yüzey çatlakları en fazla işlenen Ti-6Al-4V alaşımında görülmüştür. Ti-6Al-4V malzemenin bakır elektrotla işlenmesi, pirinç elektrotla işlemeye kıyasla daha yoğun çatlak oluşumuna neden olmaktadır.

- EEİ delik delme işleminde oluşan yüksek sıcaklığın, özellikle Ti-6Al-4V malzemesinde elementel oran değişimine neden olduğu görülmüştür.

- Yüzey pürüzlülük değerleri, Ti-6Al-4V alaşımında daha yüksektir. Ti-6Al-4V malzeme, bakır yerine pirinç elektrot kullanılarak delindiğinde yüzey pürüzlülüğü artmaktadır.

\section{KAYNAKÇA}

[1] Soboyejo, W. O., \& Srivatsan, T. S. (2006). Advanced structural materials: properties, design optimization, and applications. CRC press.

[2] Ekmekci, B. (2007). Residual stresses and white layer in electric discharge machining (EDM). Applied Surface Science, 253(23), 9234-9240.

[3] Ghanem, F., Braham, C., \& Sidhom, H. (2003). Influence of steel type on electrical discharge machined surface integrity. Journal of Materials Processing Technology, 142(1), 163-173.

[4] Keskin, Y., Halkac1, H. S., \& Kizil, M. (2006). An experimental study for determination of the effects of machining parameters on surface roughness in electrical discharge machining (EDM). The International Journal of Advanced Manufacturing Technology, 28(11-12), 1118-1121.

[5] Maji, K., \& Pratihar, D. K. (2011). Modeling of electrical discharge machining process using conventional regression analysis and genetic algorithms. Journal of Materials Engineering and Performance, 20(7), 1121-1127.

[6] Zhang, Y., Liu, Y., Ji, R., \& Cai, B. (2011). Study of the recast layer of a surface machined by sinking electrical discharge machining using water-in-oil emulsion as dielectric. Applied Surface Science, 257(14), 5989-5997.

[7] Kanlayasiri, K., \& Boonmung, S. (2007). Effects of wire-EDM machining variables on surface roughness of newly developed DC 53 die steel: Design of experiments and regression model. Journal of Materials Processing Technology, 192, 459-464.

[8] Yilmaz, O., \& Okka, M. A. (2010). Effect of single and multi-channel electrodes application on EDM fast hole drilling performance. The International Journal of Advanced Manufacturing Technology, 51(1-4), 185-194.

[9] Okka, A. M. (2011). An Experimental Investigation of Elektrical Dissharge Machining (EDM) Fast Hole Drilling of Aerospace Alloys. M.Sc. Thesis, University of Gaziantep. 